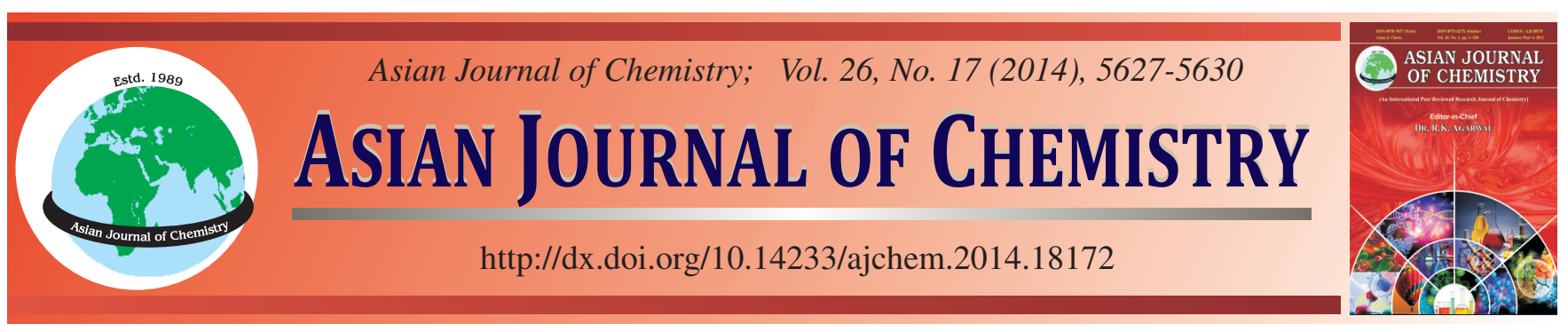

\title{
Preparation of Amorphous Coatings of AlFeCoNiCuZrV Alloy by Direct Current Magnetron Sputtering Method $\dagger$
}

\section{J. Zhang, J.B. Zhu, Z.Y. Sun and J.C. Li*}

Key Laboratory of Automobile Materials of Ministry of Education and School of Materials Science and Engineering, Jilin University, Changchun 130025, P.R. China

*Corresponding author: Fax: +86 431 85095876; E-mail: ljc@jlu.edu.cn

The amorphous coatings of $\mathrm{AlFeCoNiCuZrV}$ high entropy alloy were deposited by direct current magnetron sputtering (DCMS) in the mixed atmosphere of $\mathrm{Ar}$ and $\mathrm{O}_{2}$. A smooth amorphous coating was obtained. The microstructure and properties of the coatings were investigated. The results showed that the chemical composition, microstructure and mechanical properties of the amorphous coatings intimately relied on the concentration of $\mathrm{O}_{2}$ in the mixture atmosphere. When $\mathrm{O}_{2}$ flow ratio increased, the thickness and roughness of the coatings decreased. The maximum values of the hardness and the elastic modulus of the coating are 12 and 168 Gpa, respectively.

Keywords: High entropy alloy, Amorphous coating, Properties, Magnetron sputtering.

\section{INTRODUCTION}

The most commonly used metallic alloys are composed of one or two major elements. To improve mechanical properties, some other components are frequently added into the alloys, but in minor amount. Intermetallic compounds are gradually formed with the increase of the amount of the alloying components. Although the strength of the alloys further increases while the plasticity of the alloys dramatically drops. The complexity of such microstructures is expected not only to be responsible for their brittleness, but also for difficulties in processing and analysis. This fact has discouraged the design of new alloys with multiprincipal elements. In order to get better integrated mechanical properties, a new alloying design idea has been proposed ${ }^{1,2}$, i.e., the primary alloying elements are more than five and atomic percentage of each component is equimolar or near equimolar ratios, the alloy is called highentropy alloy (HEA). High entropy alloy contains no single matrix element. High-entropy alloys form simple microstructures, such as face center cube (FCC), body center cube (BCC), or hexagonal close packed (HCP) and no intermetallic compounds are formed. High-entropy alloy possesses characteristics as follows: sufficient high configurational entropy can conquer the effects of the heat of mixing of the alloy, which has affiliations with the number of equivalent elements. Based on Boltamann's equation, the configurational entropy of alloy can be calculated. High-entropy alloy coatings have been taken for applications in situations that requires surface protection and corrosion resistance ${ }^{3-8}$. This is due to their attractive properties, such as corrosion resistance ${ }^{9,10}$, high hardness ${ }^{11}$, high strength ${ }^{12,13}$, good wear resistance ${ }^{14,15}$ and excellent microstructure stability against heat treatment ${ }^{16-18}$.

The traditional metal nitride and oxide coatings are usually of high hardness and good corrosion resistance, but more brittle than the starting materials. Therefore, much effort has been devoted to improvement of the the hardness and brittleness of the coatings. Several hard and super-hard coatings have been reported, the hardness of the coatings reached $40 \mathrm{Gpa}$ and the toughness was good ${ }^{19}$. The analogous strengthening effect was also found in $\mathrm{VN}^{20}$. Moreover, the thermal stability of the coatings can be further improved by addition of other elements such as $\mathrm{Al}$ and $\mathrm{Si}^{21,22}$. Based on the previous investigations, the amorphous coatings of $\mathrm{AlFeCoNiCuZrV}$ high-entropy alloy were prepared. The effect of $\mathrm{O}_{2}$ flow ratio on the morphology and the mechanical properties of the coating were systematically studied.

\section{EXPERIMENTAL}

The AlFeCoNiCuZrV alloy ingot was fabricated in a vacuum furnace under argon atmosphere. The purity of all raw elemental metals was above $99.9 \%$. Then the target was machined from the ingot, the dimension of the target is $60 \mathrm{~mm}$ 
in diameter and $5 \mathrm{~mm}$ in thickness. The composition of the target by energy dispersive spectrometry (EDS) are given in Table-1. Quartz glass wafers were used as the substrates, and were cleaned sequentially in acetone, pure alcohol and deionized water. The substrates were placed about $10 \mathrm{~cm}$ from the target on the centre of a substrate table that was rotated at a speed of $5 \mathrm{rpm}$. The coatings were deposited from an AlFeCoNiCuZrV target by DC magnetron sputtering (DCMS) in the mixture atmosphere of $\mathrm{Ar}$ and $\mathrm{O}_{2}$. The technical parameters as follows: working pressure of $0.9 \mathrm{~Pa}$, plasma power of $30 \mathrm{~W}$, deposition duration of $2 \mathrm{~h}$ at room temperature. The thickness of the coatings ranged from 1-2 $\mu \mathrm{m}$. The oxygen flow ratio, $\mathrm{R}_{\mathrm{O}}=\mathrm{O}_{2} /\left(\mathrm{Ar}+\mathrm{O}_{2}\right)$, was precisely adjusted by changing the $\mathrm{O}_{2}$ flow rate. The phase analysis of the coatings was carried out using an X-ray diffractometer (XRD). The microstructure of the coatings were analyzed using field-emission scanning electron microscopy (FESEM). The hardness of the coatings was measured using a nanoindenter, meanwhile the corresponding elastic modulus was also provided.

\begin{tabular}{ccccccc}
\multicolumn{7}{c}{ TABLE-1 } \\
COMPOSITION OF THE TARGET (at. \%) \\
\hline $\mathrm{Ni}$ & $\mathrm{Cu}$ & $\mathrm{Fe}$ & $\mathrm{Co}$ & $\mathrm{V}$ & $\mathrm{Zr}$ & $\mathrm{Al}$ \\
\hline 13.2 & 13.8 & 13.9 & 13.9 & 14.6 & 15.2 & 15.3 \\
\hline
\end{tabular}

\section{RESULTS AND DISCUSSION}

Fig. 1 shows the XRD analysis of the target of AlFeCoNiCuZrV alloy. The structure of the target was $\alpha, \beta$ and $\gamma$ phases. Fig. 2 exhibits the XRD analysis of the coatings deposited with various $\mathrm{O}_{2}$ flow ratios $\left(\mathrm{R}_{\mathrm{O}}\right)$. The result shows that the structure of the coatings is amorphous. Similar results were also observed in the nitride coatings of the $\mathrm{AlCrSiTiV}^{23}$, $\mathrm{AlFeCoNiCuZrV}{ }^{24}$ and AlMoNbSiTaTiVZr ${ }^{25}$, the oxide coatings of $\mathrm{AlCoCrCu} \mathrm{Cu}_{0.5} \mathrm{NiFe}^{26}$ and AlCrTaTiZr HEA ${ }^{27}$. From Fig. 2, the patterns indicate that all the coatings are amorphous regardless of presence of oxygen in the atmosphere. Thus, the oxygen content $\mathrm{R}_{O}$ has no evident influence on the amorphous formation. However, the $\mathrm{R}_{\mathrm{O}}$ has great effect on the morphology, thickness and mechanical properties of the coatings as shown later. The reason that the deposited $\mathrm{AlFeCoNiCuZrV}$ alloy coatings were in amorphous state can be explained by the Inoue's rule ${ }^{28}$. Amorphous alloys have been investigated to understand the essential conditions for obtaining amorphous structure. The method predicted the amorphous formation ability was presented. Amorphous alloys possess higher dense randomly packed atomic configurations, new local atomic configurations and a homogeneous atomic configuration of the multicomponents on a long-range scale. Three parameters can increase amorphous formation ability of the alloys by increasing dense random packing; alloy composition consisting of more than three elements; significant difference in atomic radius is about $12 \%$ among the main alloying elements and negative heats of mixing among the alloying elements ${ }^{28}$. In addition, the combination of deposition process and atmosphere in this investigation can enhance amorphous formation ability. Fig. 3 shows the variation in compositions of the coatings with $\mathrm{R}_{\mathrm{O}}$. When $\mathrm{R}_{\mathrm{O}}=0$, each metallic element content in the coating is almost coincident with the target as given in

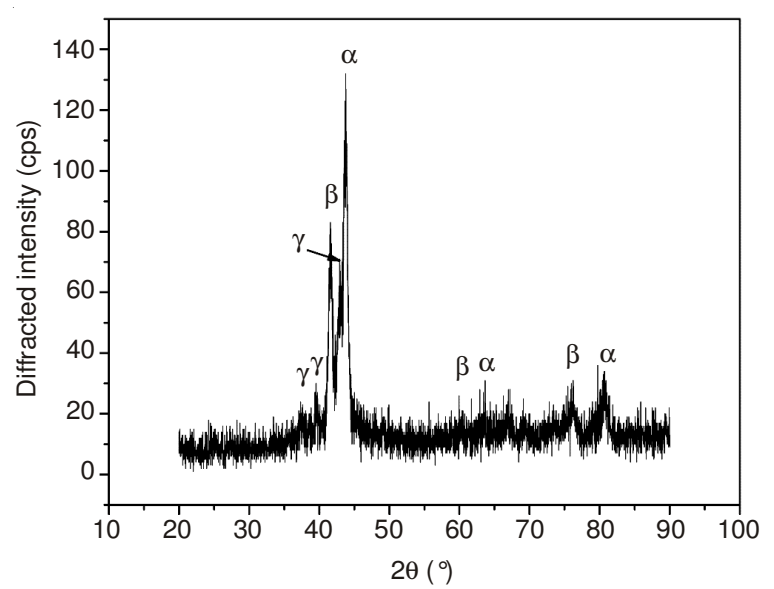

Fig. 1. XRD curve of the AlFeCoNiCuZrV target

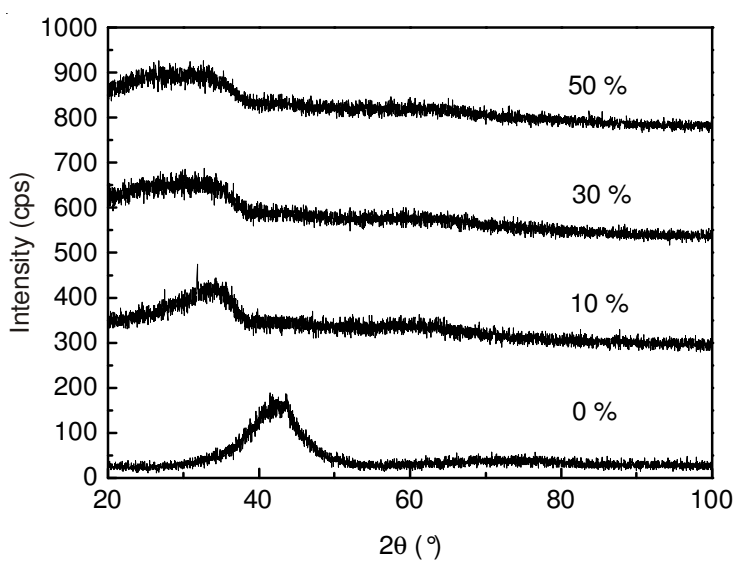

Fig. 2. XRD curves of the AlFeCoNiCuZrV oxide coatings with various $\mathrm{R}_{\mathrm{O}}$

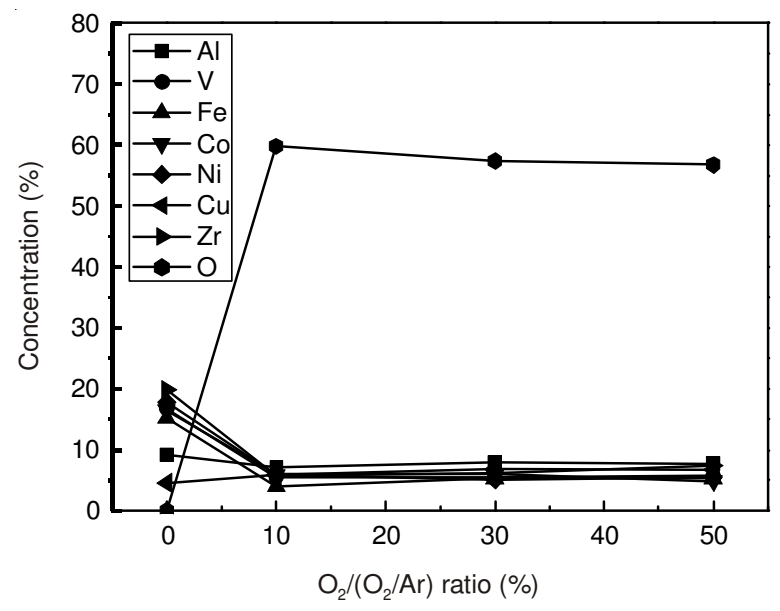

Fig. 3. Compositions of the coatings with various $R_{O}$

Table-1, except $\mathrm{Cu}$ and $\mathrm{Al}$. The content of oxygen element in the coating increased rapidly to 60 at. $\%$ with increasing the oxygen flow ratio $\left(\mathrm{R}_{0}\right)$ to $10 \%$. In comparison with the low nitrogen content of 45 at. $\%$ in the nitride coatings prepared based on the same alloy using a ratio of nitrogen flow higher than $10 \%^{7}$. It can be concluded that oxygen has a much stronger tendency to react with the individual metal atoms than nitrogen. This is also supported by the significant difference in the formation heat between the metal oxides and the metal nitrides. For example, TiN has a formation heat of $-338 \mathrm{~kJ} /$ $\mathrm{mol}^{29}$, while $\mathrm{TiO}_{2}$ has a higher formation heat of $-944 \mathrm{~kJ} / \mathrm{mol}^{30}$. 
The thickness of the AlFeCoNiCuZrV coatings deposited with various $\mathrm{R}_{\mathrm{O}}$ was listed Table- 2 . The largest thickness was $6.45 \mu \mathrm{m}$ under absence of oxygen flow condition and the smallest thickness was $1.73 \mu \mathrm{m}$ under $\mathrm{R}_{\mathrm{O}}$ of $50 \%$ condition. Incresing $\mathrm{R}_{\mathrm{O}}$ caused a decrease in thickness for the coatings. The oxide coating easily deposited on the surface of the target during sputtering due to interaction between alloying elements of the target and oxygen, hindering the particulates from depositing. This is a common phenomenon of target poisoning $^{31}$. Oxygen leads to form the oxide on the target at higher oxygen partial pressures, so that the deposited rate is decreased $^{31,32}$. In addition, when there is more $\mathrm{O}_{2}$ in the atmosphere, more amount of metallic oxide formed, the internal stress of the coating increases and inhibits further growth of the coating. Another factor, more metallic oxide were removed out of the chamber accompanying exhaust emission by vacuum pump of the direct current magnetron sputtering equipment. The growth sctructure is fundamental consequece of shadowing acting is a concert with the low adatom mobility and tends to exacerbated by the nonuiform suface topograohics encountered in microcircuit fabrication. Suppression of the voided growth strucure boundaries is important considertion for most applications.

\begin{tabular}{ccccc}
\multicolumn{6}{c}{ TABLE-2 } \\
\multicolumn{5}{c}{ THICKNESS OF THE COATINGS WITH VARIOUS $\mathrm{R}_{\mathrm{O}}$} \\
\hline $\mathrm{R}_{\mathrm{O}}$ & 0 & $10 \%$ & $30 \%$ & $50 \%$ \\
\hline Thickness $(\mu \mathrm{m})$ & 6.45 & 3.55 & 2.43 & 1.73 \\
\hline
\end{tabular}

Fig. 4 shows the FESEM micrographs of the coatings fabricated using different $\mathrm{R}_{\mathrm{O}}$. It notes that the coatings varied in the sizes of nanoparticles and geometric morphology with $\mathrm{R}_{\mathrm{O}}$. When $\mathrm{R}_{\mathrm{O}}$ is 0 , the size of nanoparticles was less than 10 $\mathrm{nm}$, but the coating was not integrated. With increasing $\mathrm{R}_{\mathrm{O}}$, the size of the nanoparticles decreased and the coating entirely covered the substrate; consequently the coating surface became smoother. A desired amorphous AlFeCoNiCuZrV coating was prepared at $\mathrm{R}_{\mathrm{O}}$ of $50 \%$, its surface appeared much smoother than the coatings obtained at other $\mathrm{R}_{\mathrm{O}}$. The improvement in the surface morphology under higher $\mathrm{R}_{\mathrm{O}}$ could be ascribed to the decrease in the deposition rate and this phenomenon agrees well with previous works ${ }^{33-36}$. However, when the $\mathrm{R}_{\mathrm{O}}$ was more than $50 \%$, the surface became rough again and the originally dense amorphous coating seemed to be incomplete. This is due to that fact that with further increasing $\mathrm{R}_{\mathrm{O}}$, the poisoning is pronounced and the deposition rate was so slow that no enough atoms deposited on the substrate. Consequently, the substrate surfaces can not be covered entirely by the coatings and there are more carvities in the coatings $\mathrm{R}_{\mathrm{O}}$ of $30-50 \%$ is the optimum ratio for fabrication of a smooth and dense amorphous $\mathrm{AlFeCoNiCuZrV} \mathrm{coating.}$

Fig. 5 shows variations in elastic modulus and hardness of the coatings with $\mathrm{R}_{\mathrm{O}}$. In case of the coating under the pure argon atmosphere, the elastic modulus and hardness were 182 and $11 \mathrm{GPa}$, respectively. When $\mathrm{R}_{\mathrm{O}}$ is $10 \%$, the elastic modulus and hardness of the coatings descrease. With sequentially increasing of $\mathrm{R}_{\mathrm{O}}$, the elastic modulus and hardness of the coatings increase. It is primarily attributed to the solidsolution strengthening, larger residual stress and denser structure. With
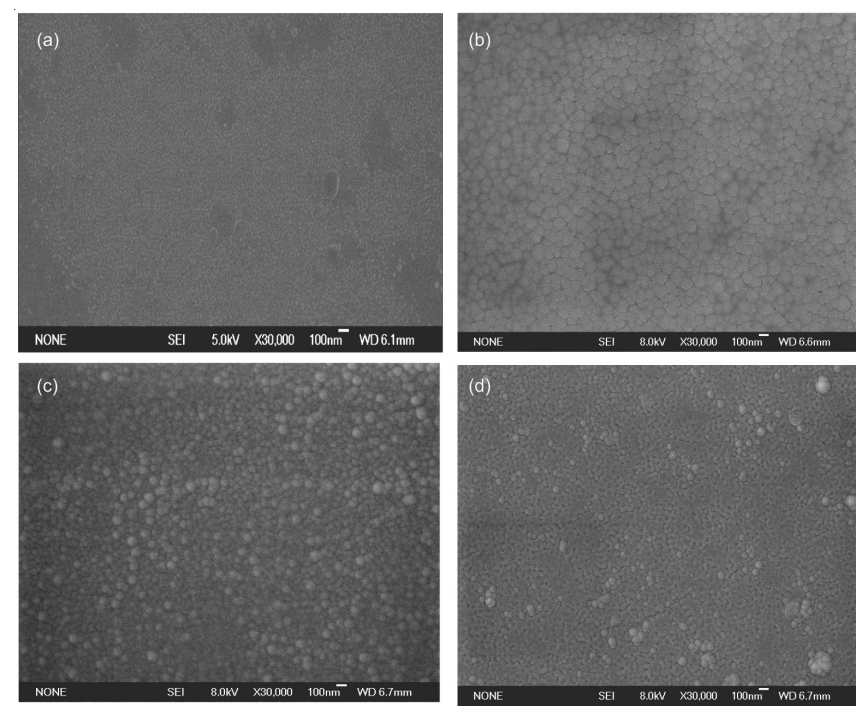

Fig. 4. FESEM photograph of the AlFeCoNiCuZrV coatings with various $R_{O}$. (a) $R_{O}=0$; (b) $R_{O}=10 \%$; (c) $R_{O}=30 \%$; (d) $R_{O}=50 \%$

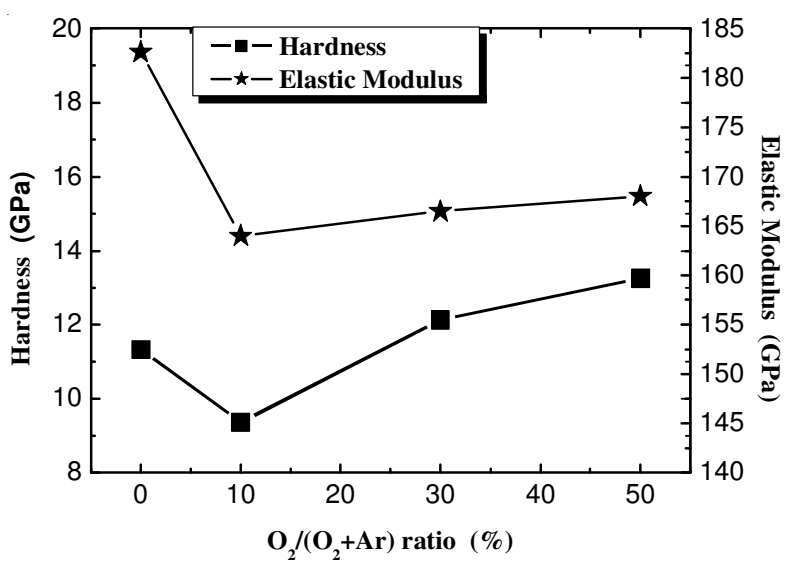

Fig. 5. Elastic modulus and hardness of the coatings

increasing the flow ratio of $\mathrm{O}_{2}$, the elastic modulus and hardness increased. The elastic modulus and hardness of the coating deposited at $\mathrm{R}_{\mathrm{O}}$ of $50 \%$ are 168 and $13 \mathrm{GPa}$, respectively.

\section{Conclusion}

The amorphous coatings were fabricated by DCMS. The oxygen content $R_{O}$ has no evident influence on the amorphous formation, but oxygen content $\mathrm{R}_{\mathrm{O}}$ plays an important role in the surface morphology. hardness and elastic modulus of the coatings. By controlling the oxygen content, the morphology and mechanical properties of the coatings can be altered. The thickness of the coatings decreased with the increasing of $\mathrm{R}_{\mathrm{O}}$. The thickness of the coatings is $1.73 \mu \mathrm{m}\left(\mathrm{R}_{O}=50 \%\right)$ and 6.45 $\mu \mathrm{m}\left(\mathrm{R}_{\mathrm{O}}=0\right)$. The elastic modulus and hardness of amorphous coating are 168 and $13 \mathrm{GPa}$, respectively.

\section{REFERENCES}

1. J.W. Yeh, S.K. Chen, S.J. Lin, J.Y. Gan, T.S. Chin, T.T. Shun, C.-H. Tsau and S.-Y. Chang, Adv. Eng. Mater., 6, 299 (2004).

2. P.-K. Huang, J.-W. Yeh, T.-T. Shun and S.-K. Chen, Adv. Eng. Mater, 6, 74 (2004).

3. S.C. Liang, D.C. Tsai, Z.C. Chang, H.S. Sung, Y.C. Lin, J.W. Yeh, M.J. Deng and F.S. Shieu, Appl. Surf. Sci., 258, 399 (2011).

4. K.H. Cheng, C.H. Lai, S.J. Lin and J.W. Yeh, Thin Solid Films, 519, 3185 (2011). 
5. S.C. Liang, Z.C. Chang, D.C. Tsai, Y.-C. Lin, H.S. Sung, M.J. Deng and F.S. Shieu, Appl. Surf. Sci., 257, 7709 (2011).

6. M.H. Tsai, J.W. Yeh and J.Y. Gan, Thin Solid Films, 516, 5527 (2008).

7. T.K. Chen, T.T. Shun, J.W. Yeh and M.S. Wong, Surf. Coat. Technol., 188-189, 193 (2004).

8. S.Y. Chang and D.S. Chen, Mater. Chem. Phys., 125, 5 (2011).

9. Y.Y. Chen, T. Duval, U.D. Hung, J.W. Yeh and H.C. Shih, Corros. Sci., 47, 2257 (2005)

10. H.K. Chen, S.H. Li and J.G. Duh, J. Electron. Mater, 34, 1480 (2005).

11. Y.J. Zhou, Y. Zhang, Y.L. Wang and G.L. Chen, Mater. Sci. Eng. A, 454-455, 260 (2007).

12. Y.J. Zhou, Y. Zhang, Y.L. Wang and G.L. Chen, Appl. Phys. Lett., 90, 181904 (2007).

13. Z. Hu, Y. Zhan, G. Zhang, J. She and C. Li, Mater. Des., 31, 1599 (2010).

14. C.-Y. Hsu, T.-S. Sheu, J.-W. Yeh and S.-K. Chen, Wear, 268, 653 (2010).

15. C. Huang, Y.Z. Zhang, R. Vilar and J.Y. Shen, Mater. Des., 41, 338 (2012).

16. B. Ren, Z.X. Liu, B. Cai, M.X. Wang and L. Shi, Mater. Des., 33, 121 (2012).

17. C.W. Tsai, Y.L. Chen, M.H. Tsai, J.W. Yeh, T.T. Shun and S.-K. Chen, J. Alloys Comp., 486, 427 (2009).

18. N. Senkov, G.B. Wilks, D.B. Miracle, C.P. Chuang and P.K. Liaw, Intermetallics, 18, 1758 (2010).

19. J. Musil, P. Karvánková and J. Kasl, Surf. Coat. Technol., 139, 101 (2001).

20. M. Uchida, N. Nihira, A. Mitsuo, K. Toyoda, K. Kubota and T. Aizawa, Surf. Coat. Technol., 177-178, 627 (2004).
21. C.W. Kim and K.H. Kim, Thin Solid Films, 307, 113 (1997).

22. C.H. Lai, S.J. Lin, J.W. Yeh and S.Y. Chang, Surf. Coat. Technol., 201, 3275 (2006).

23. C.W. Tsai, S.W. Lai, K.H. Cheng, M.H. Tsai, A. Davison, C.H. Tsau and J.W. Yeh, Thin Solid Films, 520, 2613 (2012).

24. L. Liu, J.B. Zhu, C. Hou, J.-C. Li and Q. Jiang, Mater. Des., 46, 675 (2013).

25. H.W. Chang, P.K. Huang, A. Davison, J.W. Yeh, C.-H. Tsau and C.-C. Yang, Thin Solid Films, 516, 6402 (2008).

26. Y.S. Huang, L. Chen, H.W. Lui, M.H. Cai and J.W. Yeh, Mater. Sci. Eng. A, 457, 77 (2007).

27. M.I. Lin, M.H. Tsai, W.J. Shen and J.W. Yeh, Thin Solid Films, 518, 2732 (2010).

28. A. Inoue, Mater. Trans. JIM, 36, 866 (1995).

29. H.O. Pierson, Handbook of Refractory Carbides and Nitrides, Noyes Publications, Westwood, New Jersey, P. 43 (1996).

30. J.A. Dean, Lange's Handbook of Chemistry, McGraw-Hill, New York, p. 234 (1999).

31. R.S. Mason and M. Pichilingi, J. Phys. D Appl. Phys., 27, 2363 (1994).

32. B.N. Chapman, Glow Discharge Processes, John Wiley \& Sons, New York, p. 230 (1980)

33. J.A. Thornton, J. Vac. Sci. Technol. A, 4, 3059 (1986).

34. R. Messier, V.C. Venugopal and P.D. Sunal, J. Vac. Sci. Technol. A, 18, 1538 (2000).

35. C.Z. Yao, P. Zhang, M. Liu, G.R. Li, J.Q. Ye, P. Liu and Y.-X. Tong, Electrochim. Acta, 53, 8359 (2008).

36. M.H. Tsai, C.W. Wang, C.H. Lai, J.W. Yeh and J.Y. Gan, Appl. Phys. Lett., 92, 052109 (2008). 